\title{
Effect of Different Dietary Oil Sources on Enrichment of Omega -3 Poly Unsaturated Fatty Acids in Japanese Quail Meat
}

\author{
N. Arulnathan ${ }^{1 *}$, R. Karunakaran ${ }^{2}$, M. Chellpandian ${ }^{1}$, V. Balakrishanan ${ }^{2}$ and S.T. Selvan $^{3}$ \\ ${ }^{1}$ Department of Animal Nutrition, Veterinary College and Research Institute, Tirunelveli, INDIA \\ ${ }^{2}$ Department of Animal Nutrition, Madras Veterinary College, Chennai, INDIA \\ ${ }^{3}$ Post Graduate Research Institute for Animal Sciences, Kattupakkam, INDIA \\ Tamil Nadu Veterinary and Animal Sciences University, Tamil Nadu, INDIA \\ "Corresponding author: N Arulnathan; E-mail: drarulnutri@gmail.com
}

Received: 04 Sept., 2019

Revised: 15 Oct., 2019

Accepted: 14 Nov., 2019

\section{ABSTRACT}

\begin{abstract}
An experiment was conducted to assess the effect of inclusion level of different feed ingredients rich in omega-3 fatty acids tooptimizethe production of omega-3 enriched Japanese quail meat. The feeding trial was conducted in Japanese quail broiler chicks for five weeks ( 0 - 5 week) period. The experiment had six treatments (T1-PO 4\%; T2 LO 4\%: T3 LO 3\% + SO 1\%; T4 LO $2 \%+$ SO $2 \%$; T5 LO $1 \%+$ SO $3 \%$; T6 SO 4\%) with various inclusion levels of different sources of omega-3 fatty acids (linseed oil / sardine oil) with six replicates in each treatment and each replicate had ten birds. Inclusion level of $3 \%$ linseed oil and $1 \%$ sardine fish oil was optimum for producing omega-3 fatty acids enriched Japanese quail meat. Japanese quail meat was enriched with ALA- $12.67 \%$; EPA- $2.11 \%$; DHA-2.16\% and n-3-16.95\% ( $\%$ of total fatty acids). Omega-3 fatty acids were enriched by 9.79 times and Omega- 6 : Omega-3 ratio was narrowed by 9.8 times than that of control which is ideal for human consumption.
\end{abstract}

Keywords: Japanese quail, Linseed Oil, Sardine oil, Omega-3 PUFA, Meat Enrichment

Omega 3 polyunsaturated fatty acids can be produced endogenously by humans and fish species, their biosynthesis rate is very low when compared to the physiological demand (Castro et al., 2016 and Toucher, 2015). Omega 3 polyunsaturated fatty acids are very essential component for human health and its beneficial effects on development of neural system and in preventing many more pathological conditions. These nutrients are in short supply (Naylor et al., 2009). The availability from the traditional sources to satisfy the human requirements is not enough (Tocher, 2015). It has been shown that the consumption of long chain omega-3 polyunsaturated fatty acids ensures vital components for the retina and for the membrane phospholipids of the brain (Rymer and Givens, 2006). As per the ICAR estimate, per capita consumption in India is around $3 \mathrm{~kg}$ p.a. The daily need for omega- 3 fatty acids in human consumption is $0.4-0.8 \mathrm{~g}$ on average (Leskanich and Noble, 1997). The International Society for the study of Fatty acids and Lipids recommended a daily intake of $2220 \mathrm{mg}$ of LNA and $650 \mathrm{mg}$ of EPA+DHA, with a minimum of $220 \mathrm{mg}$ both EPA and DHA (Simopoulos et al., 1999). The variety of new sources of EPA and DHA coming to market will be highly beneficial as they can be targeted to different uses and, as they all find their niche markets, this could help to draw down prices making their widespread use increasingly feasible (Toucher et al., 2019). The omega-3 polyunsaturated fatty acid content of poultry products can be enriched effectively through dietary manipulation, either directly by using fish oil, marine algae or indirectly by increasing the level of precursor of omega -3 polyunsaturated fatty acids.

Japanese quail has been used extensively as a laboratory animal as well as a commercial bird for egg and meat

How to cite this article: Arulnathan, N., Karunakaran, R., Chellpandian, M., Balakrishanan, V. and Selvan, S.T. (2019). Effect of different dietary oil sources on enrichment of Omega -3 poly unsaturated fatty acids in Japanese quail meat. J. Anim. Res., 9(6): 869-874. 
production due to its low maintenance cost associated with its small body size coupled with its short generation interval, resistance to disease and high egg production (Oguz and Minvielle, 2001; Vali, 2008). Besides, quail meat and egg are tastier than chicken with less fat content and has been shown to promote body and brain development in children and nursing mothers (Sahin et al., 2003). Japanese quail meat is a genuine alternative to other animal proteins. The valuable taste and dietary properties of quail meat are pivotal in determining the growing interest of consumers to this product. There is a great possibility to enrich quail meat with omega- 3 fatty acids through dietary manipulation to achieve the recommended daily intake of omega- 3 fatty acids in human and also to reduce the $n-6 / n-3$ ratio which is both desirable to the productivity of quails and humans consuming its meat.Moreover, dietary manipulation to produce omega-3 enriched quail meat is a novel one. Hence, this study was proposed with the objective to assess the effect of different dietary n-3 rich oil supplementation on enrichment of omega - 3 PUFA in Japanese quail meat.

\section{MATERIALS AND METHODS}

A feeding trial was conducted in Japanese quail broiler birds at Department of Animal Nutrition, Veterinary College and Research Institute, Tirunelveli, for a period of five weeks to study the effect of various inclusion levels of feed ingredients rich in omega- 3 fatty acids to produce omega-3 fatty acid enriched meat. For the feeding experiment, 360 numbers of day old Japanese quail broiler chicks belonging to a single hatch were purchased from TANUVAS Institutional Hatchery, Department Poultry Science, Veterinary College and Research Institute, Namakkal, Tamil Nadu. Upon arrival, Japanese quail chicks were wing banded, weighed individually and distributed randomly into six treatment groups (T1-PO 4\%; T2 LO 4\%: T3 LO 3\% + SO 1\%; T4 LO 2\% +SO $2 \%$; T5 LO $1 \%+$ SO 3\%; T6 SO 4\%). Six replicates of ten birds $(6 \times 10=60)$ were maintained in each treatment. The experimental birds were housed individually in two tier well ventilated battery cages provided with artificial lighting. The details of experimental design and treatments are given in Table 1 . The omega- 3 fatty acid sources - (i) Linseed oil was purchased from Falcon Essential Oil Exporters, Bangalore and (ii) Sardine fish oil was purchased from sardine fish oil processing unit,
Super Sea Foods, Thoothukudi. Palm oil purchased from local market at Tirunelveli was used in control treatment. Experimental rations were formulated as corn soya diets as per BIS (2007) specifications for Japanese quail. The rations were made iso-nitrogenous (ME: Starter-3000 $\mathrm{kcal} / \mathrm{kg}$; Finisher-2900 kcal/kg) and iso-caloric (Crude protein: Starter-28\%; Finisher-22\%). Japanese quails were fed ad libitum of their respective experimental rations in separate feed troughs. Clean drinking water was provided adlibitum initially in water trough and later in nipple drinkers. The management practices adopted were as per the standards and were uniform for all the treatments.

At the end of the feeding experiment, six birds from each treatment were slaughtered by Halal method and breast meat samples from each treatment group was taken for fatty acid profile analysis. Fatty acid profile of oil sources, experimental feed samples and Japanese quail breast meat samples was estimated as per the procedure of Palmiquist and Jenkins (2003) and expressed in percentage. Statistical analysis of experimental data was carried as per Snedecor and Cochran (1994) and by SPSS statistics for windows, version 17.0 (SPSS, 17.0, 2008).

\section{RESULTS AND DISCUSSION}

\section{Fatty acid profile of different oil sources}

The fatty acid profile of oil sources used in the experiment is presented in Table 2. Palm oil was observed to be rich in saturated fatty acids (41.28 \%) especially palmitic acid and omega-3 fatty acid content was almost negligible. Linseed oil was rich in linolenic acid $(57.43 \%)$ that was within the range of 51.23 to $57.90 \%$ as observed by various authors (Virorica et al., 2012; Surekha et al., 2010 and). The observed variation in linolenic acid content may be due to the varieties of linseed and methods followed for extraction of oil. Sardine fish oil was rich in EPA (21.73 $\%$ ) and DHA (8.36\%). These results corroborated with the reported values of $20.4 \%$ to $21.7 \%$ EPA and $11.59 \%$ to $12.2 \%$ DHA by Chitrasom and Radhakrishnan (2013) and Gamez et al. (1999) respectively. However, Ambasankar and Balakrishnan (2006) observed 13.1\% EPA and $10.61 \%$ DHA in sardine fish oil collected from western coastal area of India.

In this study in order to enrich the Japanese quail meat with omega-3 fatty acids (ALA, EPA and DHA), linseed 
Table 1: Experimental design of experiment to explore the scope for producing omega-3 enriched Japanese quail meat

\begin{tabular}{|c|c|c|c|c|c|c|}
\hline Treatments & $\begin{array}{c}\text { T1 } \\
\text { PO }-4 \%\end{array}$ & $\begin{array}{c}\text { T2 } \\
\text { LO-4\% + SO- } \\
0 \%\end{array}$ & $\begin{array}{c}\text { T3 } \\
\text { LO-3\% }+ \\
\text { SO-1\% }\end{array}$ & $\begin{array}{c}\text { T4 } \\
\text { LO-2\% }+ \text { SO- } \\
2 \%\end{array}$ & $\begin{array}{c}\text { T5 } \\
\text { LO-1\% + SO- } \\
3 \%\end{array}$ & $\begin{array}{c}\text { T6 } \\
\text { LO-0\% }+ \text { SO- } \\
4 \%\end{array}$ \\
\hline Basal diet & $\begin{array}{c}\text { Corn -soya } \\
\text { diet }\end{array}$ & $\begin{array}{c}\text { Corn - soya } \\
\text { diet }\end{array}$ & $\begin{array}{c}\text { Corn -soya } \\
\text { diet }\end{array}$ & $\begin{array}{c}\text { Corn -soya } \\
\text { diet }\end{array}$ & Corn- soya diet & $\begin{array}{c}\text { Corn -soya } \\
\text { diet }\end{array}$ \\
\hline Palm oil, \% & 4 & - & - & - & - & - \\
\hline \multicolumn{7}{|c|}{ Omega 3 fatty acid sources } \\
\hline Linseed oil, \% & - & 4 & 3 & 2 & 1 & 0 \\
\hline Sardine Fish oil, \% & - & 0 & 1 & 2 & 3 & 4 \\
\hline No. of replicates/treatment & 6 & 6 & 6 & 6 & 6 & 6 \\
\hline No. of birds/replicate & 10 & 10 & 10 & 10 & 10 & 10 \\
\hline No. of birds/treatment & 60 & 60 & 60 & 60 & 60 & 60 \\
\hline
\end{tabular}

Table 2: Fatty acid profile (in percent of total fatty acids) of different oil sources used in Japanese quail ration (Mean*)

\begin{tabular}{cccc}
\hline Fatty acid & Palm Oil & Linseed oil & Sardine Fish oil \\
\hline Myristic acid C14:0 & 1.27 & - & 13.90 \\
Palmitic acid C16:0 & $\mathbf{4 1 . 2 8}$ & 5.54 & 22.75 \\
Steraic acid C18:0 & 4.23 & 4.41 & 1.51 \\
Oleic acid C18:1 n9 & 40.69 & 17.90 & 9.28 \\
Linoleic acid C18:2 n6 & 12.28 & 13.28 & 1.57 \\
Linolenic acid C18:3 n3 & 0.22 & $\mathbf{5 7 . 4 3}$ & 0.65 \\
Arachidic acid C20:0 & - & - & 1.65 \\
Behenic acid C22:0 & - & - & $\mathbf{2 1 . 7 3}$ \\
Eicosapentaenoic acid C20:5 n3 & - & - & $\mathbf{8 . 3 6}$ \\
Docosahexaenoic acid C22:6 n3 & - & - & 1.72 .77 \\
Palmitoleic acid C16:1 & - & 1.44 & 2.91 \\
Others & - & 57.43 & 30.74 \\
Omega 3 FA & 0.22 & 13.28 & 1.57 \\
\hline
\end{tabular}

*Mean of two samples.

oil was included as it is a rich source of ALA with highest linolenic acid profile among the vegetable oil sources. But the long chain polyunsaturated fatty acids were negligible or almost nil in linseed oil. Since, the aim of this study was to enrich the Japanese quail meat with all omega-3 fatty acids, supply of LCPUFA in the diet was highly essential. Even though certain degree of elongation of ALA to EPA and DHA might happen in the bird's body, it would not be equivalent to direct supply through the diet. Hence, inclusion of sardine fish oil which is commonly available in the southern and western costal part of India and rich in EPA and DHA was selected as source of LCPUFA for the enrichment of Japanese quail meat with all omega-3 fatty acids. The combination of linseed oil and sardine fish oil was tried to explore the scope for producing omega-3 fatty acid enriched Japanese quail meat.

\section{Fatty acid profile of experimental rations}

The fatty acid profile of experimental rations to explore the scope of enrichment of omega-3 fatty acids in Japanese quail meat is presented in Table 3 .

The source and combination of various oils were reflected in the fatty acid profile of the experimental rations. T1 
Table 3: Fatty Acid Profile (in percent of total fatty acids) of Japanese Quailexperimental rations (Mean*)

\begin{tabular}{|c|c|c|c|c|c|c|}
\hline \multirow[b]{2}{*}{ Characteristics } & \multicolumn{6}{|c|}{ Fatty acid profile of Experimental ration (\%) } \\
\hline & $\begin{array}{c}\text { T1 } \\
\text { PO }-4 \%\end{array}$ & $\begin{array}{c}\text { T2 } \\
\text { LO-4\% }+ \\
\text { SO-0\% }\end{array}$ & $\begin{array}{c}\text { T3 } \\
\text { LO-3\% + SO- } \\
1 \%\end{array}$ & $\begin{array}{c}\text { T4 } \\
\text { LO-2\% + SO- } \\
2 \%\end{array}$ & $\begin{array}{c}\text { T5 } \\
\text { LO-1\% + SO- } \\
3 \%\end{array}$ & $\begin{array}{c}\text { T6 } \\
\text { LO-0\% }+ \\
\text { SO-4\% }\end{array}$ \\
\hline Myristic acid (C14:0) & 2.64 & 0.66 & 1.9 & 3.83 & 4.67 & 8.78 \\
\hline Palmitic acid (C16:0) & 27.23 & 10.49 & 12.51 & 12.94 & 11.69 & 21.73 \\
\hline Steraic acid (C18:0) & 6.63 & 4.03 & 3.5 & 1.82 & 3.09 & 4.29 \\
\hline Oleic acid (C18:1) & 36.85 & 27.95 & 26.63 & 24.63 & 25.14 & 25.4 \\
\hline Linoleic acid (C18:2) (n-6) & 21.14 & 25.64 & 26.93 & 28.92 & 26.56 & 20.39 \\
\hline Linolenic acid (C18:3) (n-3) & 0.73 & 27.63 & 22.56 & 14.08 & 1.87 & 1.2 \\
\hline Arachidic acid (C20:0) & 0.09 & 0.08 & 0.11 & 0.88 & 9.23 & 1.09 \\
\hline Behenic acid (C22:0) & 0.06 & 0.36 & 0.32 & 4.3 & 6.25 & 4.68 \\
\hline Eicosapentaenoic acid $(\mathrm{C} 20: 5)(\mathrm{n}-3)$ & 0.06 & 0.16 & 1.66 & 1.81 & 2.27 & 3.28 \\
\hline Docosahexaenoic acid (C22:6)(n-3) & 0.15 & 0.07 & 0.25 & 0.35 & 0.5 & 0.7 \\
\hline Palmitoleic acid (C16:1) & 4.2 & 2.63 & 2.73 & 5.98 & 6.89 & 9.47 \\
\hline$\Sigma$ Omega-3 fatty acids & 0.94 & 27.86 & 24.47 & 16.24 & 4.64 & 5.18 \\
\hline Omega- 6 : Omega -3 fatty acids & 22.49 & 0.92 & 1.10 & 1.78 & 5.72 & 3.94 \\
\hline
\end{tabular}

*Mean of two samples; PO-Palm oil; LO - Linseed oil; SO- Sardine fish oil.

(control) ration was rich in saturated fatty acids due to the inclusion of palm oil which is rich in saturated fatty acids. The level of linolenic acid content gradually increased according to the inclusion level of linseed oil level in the feeds. The level of long chain poly unsaturated fatty acids levels increased in the rations which may be due to increase in the inclusion level of sardine fish oil that has higher level of EPA and DHA content.

Total n-3 fatty acids ranged from 0.94 to 27.86 percent in total fatty acids present in the experimental rations. It denotes that the control ration contained very negligible percent of ALA and linseed oil included ration at $4 \%$ level was rich in ALA. Total n-6 fatty acids ranged from 20.39 to 28.92 percent in total fatty acids present in the feeds. The ratio between omega- 6 and omega- 3 was very wide in palm oil supplemented control ration and the ratios were within the recommended level in all other treatment rations.

\section{Effect of different dietary oil sources on omega-3 fatty} acids enrichment in Japanese

\section{Quail meat}

The data on fatty acid profile of breast meat in Japanese quail fed with different sources oil rich in omega-3 fatty acids are presented in Table 4.

There wasa significant $(\mathrm{P}<0.05)$ difference noticed in all fatty acid profile of meat among the treatments that was in accordance to the profile of the feed fed to the birds in the respective treatments. Linolenic acid was significantly $(\mathrm{P}<0.05)$ higher in $\mathrm{T} 2 \quad(16.90 \pm 3.22)$, T3 $(12.67 \pm 2.41)$ of total fatty acids when comparedto other treatments and control. Percent EPA acid in total fatty acid profile of Japanese quail breast meat in this experiment was significantly $(\mathrm{P}<0.05)$ higher in $\mathrm{T} 3(2.11 \pm 0.27)$, T4 (2.64 \pm 0.34$),$ T5 $(3.17 \pm 0.41)$ and T6 $(2.93 \pm 0.20)$ when compared to $\mathrm{T} 1 \quad(0.11 \pm 0.01)$ and $\mathrm{T} 2(0.53 \pm 0.06)$.Percent DHA acid in total fatty acid profile of Japanese quail breast meat was significantly $(\mathrm{P}<0.05)$ higher in $\mathrm{T} 3(2.16 \pm 0.15)$, T4 (2.71 \pm 0.18$)$, T5 $(3.25 \pm 0.22)$ and T6 $(2.86 \pm 0.18)$ when compared to $\mathrm{T} 1(0.05 \pm 0.02)$ and $\mathrm{T} 2(0.54 \pm 0.04)$.It was observed that increase in supply of n-3 fatty acids lead to significant $(p<0.05)$ reduction in $n-6$ linoleic acid content compared to control.

The incorporation of linolenic acid in the Japanese quail breast meat was significantly $(\mathrm{P}<0.05)$ higher in $\mathrm{T} 2$ and $\mathrm{T} 3$ groups than other treatments and the feed to meat transfer efficiency also was also proportionate to the fatty acid profile of the feed. Similar trend was also noticed in EPA 
Table 4: Effect of Different Sources of Omega -3 PUFA on the Fatty Acid Profile (in percent of total fatty acids) of Breast Meat in Japanese Quail (Mean* \pm SE)

\begin{tabular}{|c|c|c|c|c|c|c|}
\hline \multirow{3}{*}{ Characteristics } & \multicolumn{6}{|c|}{ Fatty Acid Profile of Japanese Quail Meat (\%) } \\
\hline & T1 & $\mathbf{T 2}$ & T3 & T4 & T5 & T6 \\
\hline & PO $-4 \%$ & $\begin{array}{c}\text { LO- } 4 \%+\text { SO- } \\
0 \%\end{array}$ & $\begin{array}{c}\text { LO-3\% + } \\
\text { SO-1\% }\end{array}$ & $\begin{array}{c}\text { LO- } 2 \%+\text { SO- } \\
2 \%\end{array}$ & $\begin{array}{c}\text { LO- } 1 \%+\text { SO- } \\
3 \% \\
\end{array}$ & $\begin{array}{c}\text { LO- } 0 \%+\text { SO- } \\
4 \% \\
\end{array}$ \\
\hline Linoleic acid (C18:2) (n-6) & $17.24^{\mathrm{b}} \pm 0.52$ & $19.08^{\mathrm{b}} \pm 0.59$ & $17.06^{\mathrm{b}} \pm 1.56$ & $11.37^{\mathrm{a}} \pm 1.04$ & $11.59^{\mathrm{a}} \pm 0.49$ & $11.39^{\mathrm{a}} \pm 0.49$ \\
\hline Linolenic acid (C18:3) (n-3) & $1.56^{\mathrm{a}} \pm 0.16$ & $16.90^{\mathrm{d}} \pm 3.22$ & $12.67^{\mathrm{cd}} \pm 2.41$ & $8.44^{\mathrm{bc}} \pm 1.61$ & $4.22^{\mathrm{ab}} \pm 0.80$ & $0.92^{\mathrm{a}} \pm 0.16$ \\
\hline Eicosapentaenoic acid $(\mathrm{C} 20: 5)(\mathrm{n}-3)$ & $0.11^{\mathrm{a}} \pm 0.01$ & $0.53^{\mathrm{a}} \pm 0.06$ & $2.11^{\mathrm{b}} \pm 0.27$ & $2.64^{\mathrm{bc}} \pm 0.34$ & $3.17^{\mathrm{c}} \pm 0.41$ & $2.93^{\mathrm{bc}} \pm 0.20$ \\
\hline Docosahexaenoic acid(C22:6)(n-3) & $0.05^{\mathrm{a}} \pm 0.02$ & $0.54^{\mathrm{b}} \pm 0.04$ & $2.16^{\mathrm{c}} \pm 0.15$ & $2.71^{\mathrm{d}} \pm 0.18$ & $3.25^{\mathrm{e}} \pm 0.22$ & $2.86^{\mathrm{de}} \pm 0.18$ \\
\hline Total Omega-3 fatty acids & $1.73^{\mathrm{a}} \pm 0.14$ & $17.97^{\mathrm{d}} \pm 3.24$ & $16.95^{\mathrm{d} \pm 2.55}$ & $13.79^{\mathrm{cd}} \pm 1.81$ & $10.64^{\mathrm{bc}} \pm 1.13$ & $6.72^{\mathrm{ab}} \pm 0.54$ \\
\hline Total PUFA & $18.97^{\mathrm{a}} \pm 0.37$ & $37.05^{\mathrm{b}} \pm 3.37$ & $34.01^{\mathrm{b}} \pm 4.11$ & $25.17^{\mathrm{a}} \pm 2.84$ & $22.24^{\mathrm{a}} \pm 1.28$ & $18.11^{\mathrm{a}} \pm 0.50$ \\
\hline Total MUFA ${ }^{\mathrm{NS}}$ & $39.44 \pm 1.02$ & $38.53 \pm 1.01$ & $37.21 \pm 0.84$ & $36.13 \pm 0.84$ & $37.72 \pm 0.61$ & $37.48 \pm 1.41$ \\
\hline Total SFA & $41.58^{\mathrm{b}} \pm 0.94$ & $27.03^{\mathrm{a}} \pm 2.28$ & $28.77^{\mathrm{a}} \pm 4.47$ & $38.69^{\mathrm{b}} \pm 2.77$ & $40.03^{\mathrm{b}} \pm 1.65$ & $44.40^{\mathrm{b}} \pm 1.50$ \\
\hline Omega-6/omega- 3 FA & $10.18^{\mathrm{b}} \pm 0.74$ & $1.14^{\mathrm{a}} \pm 0.23$ & $1.03^{\mathrm{a}} \pm 0.72$ & $0.83^{\mathrm{a}} \pm 0.04$ & $1.11^{\mathrm{a}} \pm 0.12$ & $1.72^{\mathrm{a}} \pm 0.18$ \\
\hline
\end{tabular}

* Mean of six observations.

Mean values having different alphabets in a row differ significantly $(\mathrm{P}<0.05)$.

PO-Palm oil; LO - Linseed oil; SO- Sardine fish oil; PUFA-Poly unsaturated fatty acids.

MUFA-Mono unsaturated fatty acids; SFA- Saturated fatty acids.

and DHA. But the transfer efficiency is low in EPA and DHA when compared to linolenic acid.

There was significant $(\mathrm{P}<0.05)$ reduction in linoleic acid per cent in total fatty acids noticed while the n-3 fatty acids increases. This might be due the competition for the enzymes that are required for elongation and desaturation between alpha linoleneic acid (n-3) and linoleic acid. Total omega-3 fatty acids are significantly high in T2 and T3.It indicates the higher transfer efficiency or incorporation of linolenic acid in Japanese quail meat from feed. The omega-6 and omega -3 ratio was significantly low in all treatment groups (T2 to T6) supplemented with omega-3 rich oil sources either linseed oil or sardine fish oil or combination of both in different percent that total inclusion level not exceeding 4 percent in the diet. This ratio is within the range of recommended ideal ratio for human consumption.

In this present study, the n-3 fatty acids linolenic, EPA and DHA in the breast meat increased significantly $(\mathrm{P}<0.05)$ linearlywith increase in the feed through the oil supplementation which were rich in the respective omega-3 fatty acids. The transfer efficiency was high for ALA in linseed oil supplementation than the sardine oil supplementation (EPA and DHA). And the incorporation of long chain fatty acids (EPA and DHA) in the Japanese quail meat was proportionate to the sardine fish oil inclusion in the feed. Apart from the direct transfer of LCPUFA to the meat from feed, the elongation of ALA to form EPA and DHA was high when the ALA supplementation was low (T4 and T5), as corroborated by the results of Surekha et al. (2010). Poly unsaturated fatty acids content was significantly higher in young (5 weeks old) Nandanam Quail-III than adult (27 weeks) (Ilavarasan et al. (2016).

This study revealed that the inclusion level of linseed oil (3\%) and sardine fish oil (1\%) is optimum for producing omega-3 fatty acids enriched Japanese quail meat. Japanese quail meat was enriched by ALA- 12.67\%; EPA-2.11\%; DHA-2.16 \%; n-3-16.95\% (\% of total fatty acids). Omega-3 fatty acids were enriched by 9.79 times than control and omega- 6 : omega- 3 ratio was reduced by 9.8 times than that of controland the Omega-6: Omega-3 (1.03) ratio is ideal for human consumption.

\section{REFERENCES}

Ambasankar, K. and Balakrishan, V. 2006. Indian sardine oil (Sardinella logiceps) as a source of omega-3 fatty acids. Anim. Nutr. Feed Techn., 6: 283-287. 
Castro, L.F.C., Tocher, D.R. and Monroig, O. 2016. Long-chain polyunsaturated fatty acid biosynthesis in chordates: Insights into the evolution of fads and elovl gene repertoire. Prog. Lipid Res., 62: 25-40.

Chitrasom, R.S. and Radhakrishnan, C.K. 2013. Seasonal variation in the fatty acid composition of Sardinella longiceps and Sardinella fimbriata: Implication for nutrition and pharmaceutical industry. Ind. J. Geo marine Sci., 42: 206- 210

Gamez Meza, N., Higuera Ciapara, I.,. Calderon de la Barca, A.M., Vazquez Moreno, L., Noriega Rodriguez, J. and Angulo Guerrero, O. 1999. Seasonal variation in the fatty acid composition and quality of sardine oil from Sardinops saga $\times$ caeruleus of the Gulf of California. Lipids, 34: 639642 .

Illavarasan, R., Robinson, J.J. Abraham and Appa Rao, V. 2016. The Relationship Between Meat quality Charactersistics and Nutritional Composition of Nandanam Quail-III Slaughtered at Different Ages. J. Anim. Res., 6(2): 95-100.

Leskanich, C.O. and Noble, R.C. 1997. Manipulation of the n-3 polyunsaturated fatty acid composition of avian eggs and meat. World Poult. Sci. J., 53: 155.

Naylor, R.L., Hardy, R.W., Bureau, D.P., Chiu, A., Elliot, M., Farrell, A.P., Forster, I., Gatlin, D.M., Goldburg, R.J., Hua, K., et al. 2009. Feeding aquaculture in an era of finite resources. Proc. Natl. Acad. Sci. USA, 106: 15103-15110.

Oguz, I. and Minvielle, F. 2001. Effects of genetics and breeding on carcass and meat quality of Japanese quail: A review Proceedings of XV European symposium on the quality of poultry meat, WPSA Turkish branch, 9- 12 September Kusadasi-Turkey.

Palmiquist, D.L. and Jenkins, T.C. 2003. Challenges with fat and fatty acid methods. Journal of Animal Science, 81: 32503254.
Rymer, C. and Givens, D.I. 2006. Effect of species and genotype on the efficiency of enrichment of poultry meat with n-3 polyunsaturated fatty acids. Lipids, 41: 445-451.

Sahin, K., Sahin, N. and Kucuk, O. 2003. Effects of chromium and ascorbic acid supplementation on growth, carcass traits, serum metabolites and antioxidant status of broiler chickens reared at a high ambient temperature $\left(32^{\circ} \mathrm{C}\right)$. Nutr. Res., 23: 225-238.

Simopoulos, A.P., Leaf, A. and Salem Jr, N. 1999. Workshop on the essentiality of and recommended dietary intakes for omega-6 and omega-3 fatty acids. J. Am. Coll. Nutr., 18: 487-489.

Simopoulos, A.P. 2001 Evolutionary aspects of diet, essential fatty acids and cardiovascular disease. European Heart $J$. Supplem., 3: D8-D21.

Snedecor, G.W. and Cochran, W.G. 1994. Statistical Methods. $8^{\text {th }}$ ed. Iowa State University press, Iowa. USA.

SPSS, 2008. Statistical Package for Social Science (SPSS) for windows, Version 7.00. Chicago, IL, USA: SPSS Inc.

Surekha, B, Hegde, M., Ranade, A., Avari, P., Nikam, S. Kshirsagar, K. and Kadam, S. 2010. Studies in the production of omega-3 enriched chicken meat: II. Indian J. Poult. Sci., 45: 273-279.

Tocher, D.R. 2015. Omega-3 long-chain polyunsaturated fatty acids and aquaculture in perspective. Aquaculture, 449: 94107.

Vali, N. 2008. The Japanese quail: A review. Inter. J. Poult. Sci., 7: $925-931$.

Viorica-Mirela Popa, Alexandra Gruia, Diana-Nicoleta Raba, Delia Dumbrava, Camelia Moldovan, Despina Bordean and Constantin Mateescu. 2012. Fatty acids composition and oil characteristics of linseed (Linum Usitatissimum L.) from Romania. J. Agro. Proand Tech., 18: 136-140. 